but essential service - energy - in as simple ways as are consistent with economic, environmental and social goals. Continuing experimental and analytical studies of laser fusion seem to be raising the technological ante for success faster than budgets, technology, and perhaps even science, can cope.

As to the characters and events themselves, Heppenheimer sometimes tells us too much - nine pages on a fight about whether an advance in achieved plasma energy was to be publicized, for instance. Are we really so interested in the appearance of the last part of Sir Galahad's horse to leave the stable? But in his last chapter, and occasionally elsewhere, Heppenheimer catches the spirit that inspired the pioneers in this enterprise. They were among the most brilliant of scientists, both in the United States and elsewhere, and did what they did because it was, in some deep way, a good thing for society to do. Some of that spirit still exists; without it, the quest will surely fail.

David J. Rose is a Professor of Nuclear Engineering at the Massachusetts Institute of Technology.

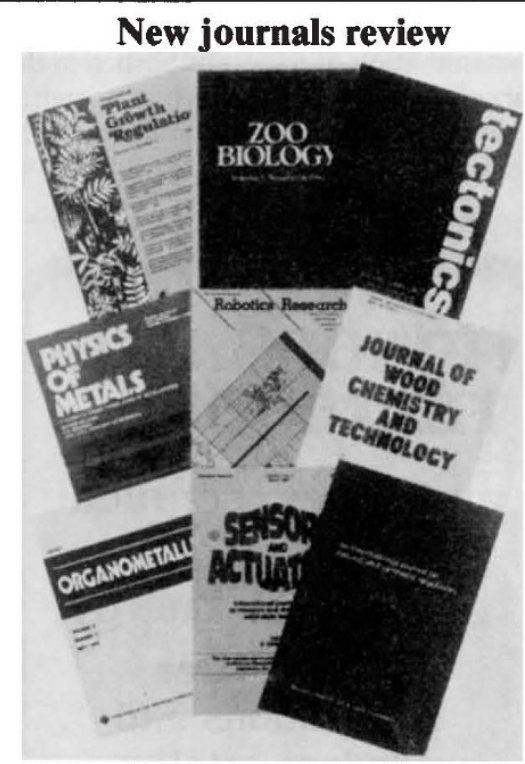

On 27 September Nature will publish the fourth annual review supplement devoted to science journals.

Criteria for inclusion of a journal in the 1984 issue are that:

(i) the first number appeared, or the journal was retitled, between June 1982 and May 1983 (the second cut-off date allows at least three issues of a journal to have been published, the minimum number on which a reasonable judgement can be based);

(ii) it is published at least three times a year;

(iii) the main language used is English.

Publishers and learned societies are invited to send four different issues of each suitable periodical, including the first and most recent numbers (if from outside the United Kingdom, by air mail) to: The Review Editor, Nature, 4 Little Essex Street, London WC2R 3LF, England. Subscription details, if possible for both 1984 and 1985, should be included.

\section{A different sort of Darwinism}

\section{J. H. Brooke}

Darwin and the Spirit of Man.

By Alister Hardy.

Collins: 1984. Pp.245. £9.95.

SIR Alister Hardy is prominent among those who have argued for "Darwinism with a difference"'. Whilst acknowledging the creative powers of natural selection, he enshrines innovative behaviour as a distinctive selective force. His argument is that a learnt and beneficial habit can be instrumental in structural selection by favouring subsequent genetic change which might reinforce the behavioural novelty. In the approved words of R.F. Ewer: "behaviour will tend to be always one jump ahead of structure and so play a decisive role in the evolutionary process".

From such a possibility, Sir Alister advances the claim that behavioural selection has been one of the "major factors" in the evolution of birds and mammals. His sights are set on what he considers an "intellectual scandal" - the notion that Darwinian evolution can only be construed in materialist and reductionist terms. Using results from his Religious Experience Research Unit, his aim is to present an alternative synthesis which does justice both to the integrity of biological explanation and the reality of religious experience. So urgent a purpose in so distinguished a figure deserves serious consideration.

Informal in style, almost evangelistic in tone, the exposition strives for intellectual unity in a manner which strikes one as more impressionistic than formally rigorous. Even non-specialists may be perplexed by the way Sir Alister structures his alternatives. The reader is asked to choose between a chance mutation or a new habit as the instigator of adaptive change. Sir Alister's heart is with the latter, elevating the conscious, explorative and perceptive aspects of animal behaviour. But may not the choice itself be misleading? If a bird learns a new trick, even how to raid a milk-bottle, the capacity to learn was presumably already there in the genecomplex, having been encouraged by past selection. And if the new behaviour continued to be advantageous, it would presumably be favoured, again by the normal process of selection. Conversely, a mechanism whereby genetic change $s u b$ sequently reinforced a behavioural innovation might invite the objection that it could destroy a useful flexibility of response. The new habit, if genetically and structurally "fixed", might sacrifice versatility for a precarious short-term gain.

A constrictive choice is also presented in the treatment of consciousness: either an extreme reductionism, in which conscious- ness is epiphenomenal; or a form of psychophysical dualism, affirmed on eminent authority but largely assumed by Sir Alister rather than specifically argued for. Excluded by this dichotomy would be those monistic accounts which treat consciousness as an "emergent" property, associated with a particular degree of material organization, but neither reducible to it nor the product of an elusive spiritual element. It is Sir Alister's view that the spiritual element is not, after all, elusive. It exists in all mankind and may be discerned in numerous reports describing a

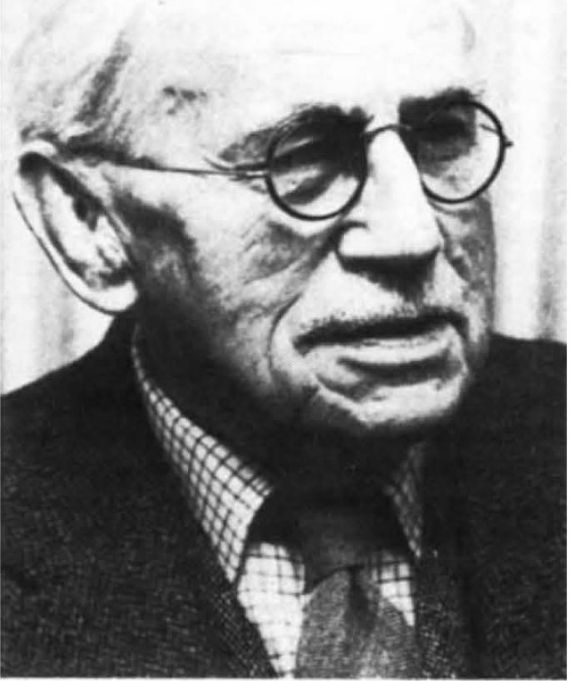

Sir Alister Hardy - "Whilst acknowledging the creative powers of natural selection, he enshrines innovative behaviour as a distinctive selective force"

"feeling of receiving help from a power, from Divinity, beyond the self".

The perplexity here is that whilst the author offers a sensitive classification of reported experiences, it is not shown how, from reports alone, one can establish anything further than the point that such feelings of dependence are common. The counterpoise is still that which weighed so heavily with the young Charles Darwin as he studied the natives of Tierra del Fuego: such feelings were apparently not shared by, and therefore not essential to, all humanity. The further suggestion that this sense of drawing upon a power outside the self might have become an energizing force in human evolution, a "something that gave more courage than [men] had ever had before", is not without difficulty. Might that sense of dependence not just as easily encourage passivity as activity? Alternatively, supposing it had gradually been reinforced by its survival value, would that really persuade us that man's spiritual nature had any transcendental significance? But whatever one's response to Sir Alister's confessedly personal view, it is stimulating to engage his own burning questions.

J.H. Brooke is a Senior Lecturer in History of Science and Principal of Bowland College, University of Lancaster. 